\title{
Near-Infrared Spectroscopy Study of Serpentine Minerals and Assignment of the OH Group
}

\author{
Shaokun $\mathrm{Wu}^{1}{ }^{1}$, Mingyue He ${ }^{1, *}$, Mei Yang ${ }^{2}$, Biyao Zhang ${ }^{1}$, Feng Wang ${ }^{3}$ and Qianzhi $\mathrm{Li}^{3}$ \\ 1 Gemological Institute, China University of Geosciences, Beijing 100083, China; \\ 3009210005@email.cugb.edu.cn (S.W.); zhangby889@163.com (B.Z.) \\ 2 Sciences Institute, China University of Geosciences, Beijing 100083, China; yangmei@cugb.edu.cn \\ 3 Shaanxi Mine in Hanyuan Jade Industry Co., Ltd., Hanzhong 723000, China; \\ wang13891685963@163.com (F.W.); qianzhili2021@163.com (Q.L.) \\ * Correspondence: hemy@cugb.edu.cn
}

check for updates

Citation: Wu, S.; He, M.; Yang, M.; Zhang, B.; Wang, F.; Li, Q.

Near-Infrared Spectroscopy Study of Serpentine Minerals and Assignment of the OH Group. Crystals 2021, 11, 1130. https://doi.org/10.3390/ cryst 11091130

\section{Academic Editors: Sergey}

V. Krivovichev, Taijin Lu, Fei Liu and Tingting Gu

Received: 27 July 2021

Accepted: 12 September 2021

Published: 17 September 2021

Publisher's Note: MDPI stays neutral with regard to jurisdictional claims in published maps and institutional affiliations.

Copyright: (c) 2021 by the authors. Licensee MDPI, Basel, Switzerland. This article is an open access article distributed under the terms and conditions of the Creative Commons Attribution (CC BY) license (https:/ / creativecommons.org/licenses/by/ $4.0 /)$.
Abstract: Three different kinds of serpentine mineral samples were investigated using Fourier transform near-infrared spectroscopy (FTNIR). The results show that there are obvious differences in the characteristic infrared spectra of the three serpentine group minerals (lizardite, chrysotile, and antigorite), which can easily be used to identify these serpentine minerals. The combination of weak and strong peaks in the spectrum of lizardite appears at 3650 and $3690 \mathrm{~cm}^{-1}$, while the intensities of the peaks at 4281 and $4301 \mathrm{~cm}^{-1}$ (at 7233 and $7241 \mathrm{~cm}^{-1}$, respectively) are similar. A combination of weak and strong peaks in chrysotile appears at 3648 and $3689 \mathrm{~cm}^{-1}$ and at 4279 and $4302 \mathrm{~cm}^{-1}$, and a single strong peak appears at $7233 \mathrm{~cm}^{-1}$. In antigorite, there are strong single peaks at 3674,4301 , and $7231 \mathrm{~cm}^{-1}$, and the remaining peaks are shoulder peaks or are not obvious. The structural $\mathrm{OH}$ mainly appears as characteristic peaks in four regions, 500-720, 3600-3750, 4000-4600, and $7000-7600 \mathrm{~cm}^{-1}$, corresponding to the $\mathrm{OH}$ bending vibration, the $\mathrm{OH}$ stretching vibration, the $\mathrm{OH}$ secondary combination vibration, and the $\mathrm{OH}$ overtone vibration, respectively. In the combined frequency vibration region, the characteristic peak near $4300 \mathrm{~cm}^{-1}$ is formed by the combination of the internal and external stretching vibrations and bending vibrations of the structural OH group. The overtone vibrations of the $\mathrm{OH}$ stretching vibration appear near $7200 \mathrm{~cm}^{-1}$, and the practical factor is about 1.965. The near-infrared spectra of serpentine minerals are closely related to their structural differences and isomorphous substitutions. Therefore, near-infrared spectroscopy can be used to identify serpentine species and provides a basis for studies on the genesis and metallogenic environment of these minerals.

Keywords: near-infrared spectroscopy; lizardite; chrysotile; antigorite; $\mathrm{OH}$ group

\section{Introduction}

Infrared spectroscopy can be a powerful tool for identifying compounds, crystal structure and isomorphism. In geology, mid-infrared and near-infrared spectroscopy are commonly used for research. Mid-infrared (MIR) generally refers to the infrared spectrum in the range $400-4000 \mathrm{~cm}^{-1}(25-2.5 \mu \mathrm{m})$. Among them, the $1500-4000 \mathrm{~cm}^{-1}$ region can identify the characteristic fundamental frequency vibration of some groups. The 400-1500 $\mathrm{cm}^{-1}$ region is called the "fingerprint area" [1], which can identify specific molecular structure from their spectrum. The near-infrared spectrometer was available as early as the 1920s, long before the popularization of the mid-infrared spectrometer laboratory [2]. Near-infrared (NIR) generally refers to the infrared spectrum in the range $4000-12,500 \mathrm{~cm}^{-1}(2.5-1 \mu \mathrm{m})$. It has been widely used in agriculture, the chemical industry, and other fields due to its fast and non-destructive characteristics [3-6]. In geology, nearinfrared spectroscopy mainly reflects the combination bands and overtone bands of water or different functional groups in minerals structure, as well as the combination modes of the hydroxyl group and metal ions, which can reflect the differences in the composition 
and structure of minerals. Therefore, it is very useful for the identification and study of minerals.

Serpentine minerals are trioctahedral phyllosilicates type 1:1 and consist of $\mathrm{SiO}_{4}$ tetrahedral sheets and octahedral brucite-like sheets. They produce different structures because of the lattice mismatch between the octahedral $(\mathrm{O})$ and the tetrahedral $(\mathrm{T})$ sheets. The compensation for this mismatch occurs through chemistry changes or through curvature of the layers [7]. Based on these different structures, serpentine can be divided into three types: lizardite, antigorite, and chrysotile. Lizardite has a flat crystal structure, where the planar sheet presents an ideal layer topology. Antigorite shows a corrugated wavy layer characterized by a modulated structure. Chrysotile with the cylindrical spiral wrapping of the 1:1 layer exhibits a fibrous structure. Naturally occurring intergrowths of the three types of serpentine minerals are very common. Among the conventional techniques used to identify serpentine minerals without losing microstructural information, only Transmission Electron Microscopy with EDS (TEM-EDS) gives unambiguous results; however, sample preparation is complex and time-consuming, and the interpretation of the electron diffraction patterns is not easy [8]. Therefore, it is necessary to find a simple characterization technique to identify and distinguish between these three minerals.

Infrared spectroscopy is a powerful tool for quickly identifying different types of clay minerals. The IR spectra of phyllosilicates have been summarized by Farmer [9]. Serpentines exhibit $v \mathrm{OH}\left(\mathrm{OH}\right.$-stretching) bands in the range $3650-3700 \mathrm{~cm}^{-1}$ and $\delta \mathrm{OH}$ (OH-vibrating) bands near 618 and $646 \mathrm{~cm}^{-1}$, due to their inner and surface hydroxyls [9]; however, there is no specific distinction between the peaks of the inner and surface hydroxyl groups. Cheng et al. [10] measured and distinguished five phyllosilicate minerals using near-infrared spectroscopy, including pyrophyllite, muscovite, talc, chrysotile, and kaolinite. Li et al. [11] analyzed the near-infrared spectra of different types of silicate minerals and concluded that there were different types of combined frequency and double-frequency peaks for water in gem minerals. Zhang et al. [12] compared TO- and TOT-type layered silicates and found that layered silicates have a long hydrogen bond, which widens the stretching vibration band of $\mathrm{O}-\mathrm{H}$, shifts the band in the direction of the long wave, and sometimes causes double-peak phenomenon to appear. The stretching frequency of the hydroxyl group is also affected by the octahedral cation coordinated with the hydroxyl group.

The purpose of this study is to demonstrate the differences in the near-infrared spectra of three types of serpentines and to discuss the assignments of the major near-infrared bands, which can be used to quickly identify and distinguish between serpentine group minerals. The results of this study are applicable to the identification and research of jewelry, jade, and cultural relics. In addition, the attribution of the $\mathrm{OH}$ group's vibration spectrum peak is discussed in detail, which is applicable to investigations of the metallogenic environments and compositional differences of serpentine. Finally, careful measurements and thoughtful interpretations of the infrared spectra of clay minerals may be critical to the interpretation of remotely sensed data from the Earth and Mars.

\section{Materials and Methods}

The experimental samples were divided into three groups according to their mineral type. The lizardite and chrysotile (asbestos) samples were from the Hanzhong area, Shaanxi Province, China; the antigorite samples were from the Xiuyan area, Liaoning Province, China. The refractive index of each sample was between 1.55 and 1.56; the specific gravity was between 2.56 and 2.61. Typical mineral samples were selected from the three groups for this study. The uniform part of each sample, without other phases, was used for the experiments.

SEM-EDS analyses of the serpentine samples before this study showed all samples contain the isomorphic element iron, which is very common in serpentine minerals. There are few other kinds of isomorphic elements (Table 1). 
Table 1. Mineral composition of the samples.

\begin{tabular}{ccccc}
\hline Samples & Minerals & Form & Color & Isomorphism \\
\hline DWH14-lz & & Block & Yellow & $\mathrm{Fe} / 0.7 \%, \mathrm{Al} / 0.1 \%$ \\
ZH41-lz & Lizardite & Block & Brownish yellow & $\mathrm{Fe} / 0.9 \%$ \\
Z3-lz & & Block & Brown & $\mathrm{Fe} / 1.0 \%, \mathrm{Mn} / 0.1 \%, \mathrm{Al} / 0.1 \%$ \\
SZ17-lz & & Block & Dark brown & $\mathrm{Fe} / 0.8 \%, \mathrm{Mn} / 0.2 \%, \mathrm{Al} / 0.1 \%$ \\
SM-ctl & Chrysotile & Fiber & Brown & $\mathrm{Fe} / 0.7 \%, \mathrm{Mn} / 0.1 \%, \mathrm{Al} / 0.2 \%$ \\
H7-atg & Antigorite & Block & Light yellow & $\mathrm{Fe} / 0.4 \%, \mathrm{Al} / 0.1 \%$ \\
H11-atg & & Block & Colorless & $\mathrm{Fe} / 0.3 \%$ \\
\hline
\end{tabular}

The X-ray diffraction (XRD) data were acquired using the SmartLab X-ray powder diffractometer at the Institute of Earth Science, China University of Geosciences, Beijing (CUGB). The system was equipped with a conventional copper target $\mathrm{X}$-ray tube (set to $45 \mathrm{kV}$ and $200 \mathrm{~mA}$ ) and a graphite monochromator, with a stepping-scanning mode with a scanning speed of $4^{\circ} / \mathrm{min}$ and a step length of $0.02^{\circ}$ in the range 3-90 $0^{\circ}$. The testing temperature was $15{ }^{\circ} \mathrm{C}$ and the humidity was $22 \%$. The samples were pulverized to 200 mesh powders using an agate mortar and stored immediately in a plastic bag to minimize contamination and oxidation. The results were normalized and analyzed using the MDI Jade 6.5 software and the International Center of Diffraction Database (ICDD).

The Fourier transform near-infrared spectroscopy (FTIR) measurements were performed using the Bruker Tensor II spectrometer at the National Infrastructure of Mineral, Rock, and Fossil Resources for Science and Technology (NIMRF). The spectra were collected in the frequency ranges of $400-4000 \mathrm{~cm}^{-1}$ (MIR) and $4000-10,000 \mathrm{~cm}^{-1}$ (NIR) using the $\mathrm{KBr}$ compression transmission method, with a resolution of $4 \mathrm{~cm}^{-1}$, and 64 scans were accumulated to improve the signal to noise ratio. The testing temperature range was $10-23{ }^{\circ} \mathrm{C}$, and the humidity was less than $22 \%$. The NIR data were processed by baseline removal and normalization.

The regions of $520-700 \mathrm{~cm}^{-1}$ and $3600-3800 \mathrm{~cm}^{-1}$ in the mid-infrared (MIR) were complex and the PeakFit v4.12 software was used to fit the peaks in order to find the exact locations of their component peaks. All of the spectra were fitted using a combined Gauss-Lorentz Area function, with $\mathrm{r}^{2}>0.99$.

\section{Results}

\subsection{X-ray Diffraction}

The XRD patterns of the seven selected serpentine minerals with standard XRD patterns are shown in Figure 1. The samples DWH14-lz, ZH-41-lz, Z-3-lz, and SZ-17-lz have patterns identical to that of PDF 86-0403, strong peaks at $\mathrm{d}_{(001)}=12.079-12.099^{\circ}$ and $\mathrm{d}_{(002)}=24.301-24.340^{\circ}$ and medium intensity peaks at $\mathrm{d}_{(-1-11)}=35.861-35.919^{\circ}$, which is the characteristic pattern of lizardite-1T. The sample SM-ctl has a pattern identical to that of PDF 27-1275, showing strong peaks at $\mathrm{d}_{(002)}=12.020^{\circ}$ and $\mathrm{d}_{(004)}=24.300^{\circ}$, which is the characteristic pattern of chrysotile. The pattern has fewer but wider peaks and the shape of the peak at $d_{(020)}=19.500^{\circ}$ is asymmetric. The samples H7-atg and H11-atg have patterns identical to that of PDF 07-0417, which is the characteristic pattern of antigorite. The patterns are clear and strong (the weak peak is not obvious after normalization), with strong peaks at $\mathrm{d}_{(001)}=12.159-12.160^{\circ}$ and $\mathrm{d}_{(002)}=24.580-24.599^{\circ}$. There is a double peak near $\mathrm{d}_{(-131)}=35.500-35.520^{\circ}$ and $\mathrm{d}_{(211)}=37.022-37.043^{\circ}$. All of the samples were found to be almost pure minerals without any other phases.

\subsection{Characteristics of MIR}

In the mid-infrared range, there are four main spectral bands: $400-500 \mathrm{~cm}^{-1}$, $520-700 \mathrm{~cm}^{-1}, 850-1100 \mathrm{~cm}^{-1}$, and $3600-3800 \mathrm{~cm}^{-1}$. The position, intensity, and number of spectral peaks are very consistent with the standard spectra of serpentine minerals (Figure 2), and no additional peaks appear, indicating that all of the samples are mainly composed of serpentine minerals. 


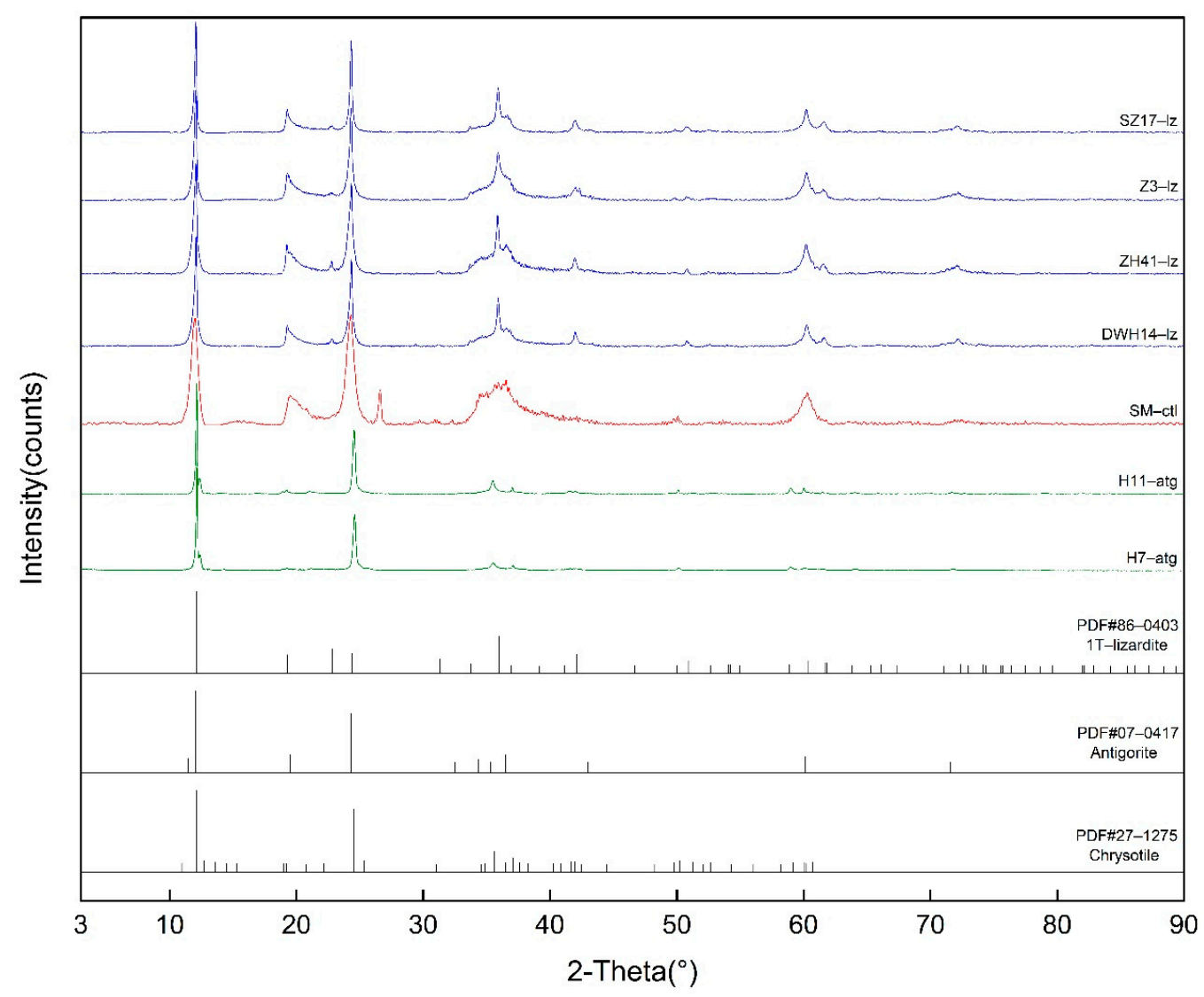

Figure 1. Powder XRD patterns of the samples.
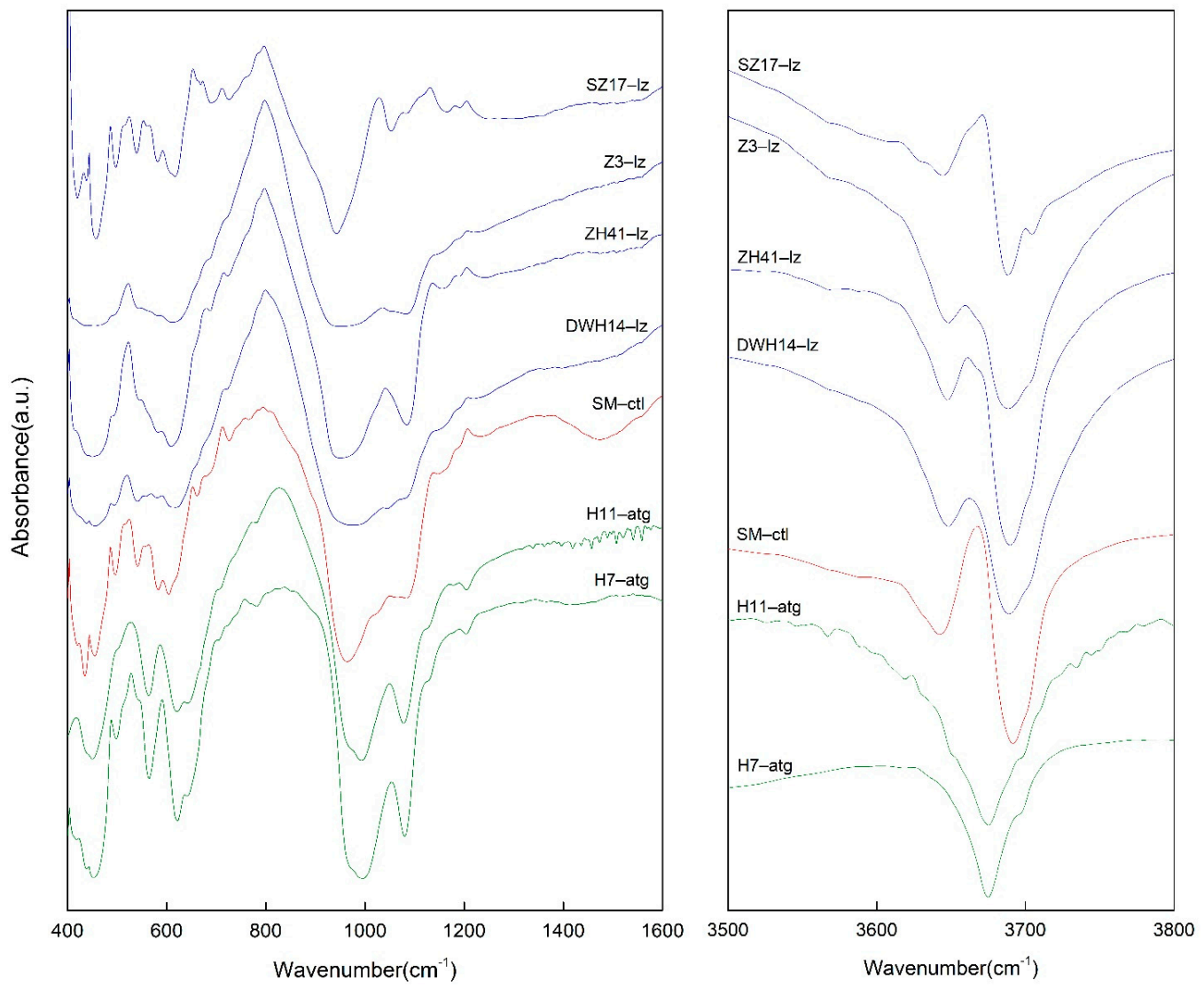

Figure 2. MIR spectra of the serpentine samples. 
There are five peaks in the range $520-700 \mathrm{~cm}^{-1}$. The spectra of DWH14-lz, ZH41-lz, Z3-lz, SZ17-lz and SM-ctl are similar, with two peaks related to $\mathrm{SiO}_{4}$ tetrahedral deformation vibration near 550 and $580 \mathrm{~cm}^{-1}$ and the strongest peak near $609 \mathrm{~cm}^{-1}$. There is only one absorption peak at $564 \mathrm{~cm}^{-1}$ for H7-atg and H11-atg, and there is a new peak at $666 \mathrm{~cm}^{-1}$, which is different from the other five samples. The bending and translation vibration peaks of $\mathrm{OH}$ in antigorite are generally four to ten wavenumbers lower than those for lizardite and chrysotile.

The peaks in the range of $3600-3800 \mathrm{~cm}^{-1}$ are usually attributed to $\mathrm{OH}$ stretching vibrations. The outer sloping $\mathrm{OH}$ stretching vibration of the serpentine minerals is at about $3650 \mathrm{~cm}^{-1}$ and the vertical stretching vibration of the outer $\mathrm{OH}$ group is around 3670 and $3690 \mathrm{~cm}^{-1}$ [13-16]. Antigorite has a unique small peak at $3632 \mathrm{~cm}^{-1}$ and the stretching vibration of the inner $\mathrm{OH}$ group near $3700 \mathrm{~cm}^{-1}$ is not present. This may be due to the periodically symmetric structure, which causes the inner $\mathrm{OH}$ vibrations to cancel each other.

Bishop [17] reported that the center of the $\mathrm{OH}$ bending vibrations were located at $606 \mathrm{~cm}^{-1}$ for chrysotile and at $625 \mathrm{~cm}^{-1}$ for lizardite. After fitting the peaks, it was found that the vibration peaks of the $\mathrm{OH}$ groups in the three types of serpentines were similar, with peaks at 609,630 , and $649 \mathrm{~cm}^{-1}$, but their strengths varied significantly. Figure 3 shows DWH14-lz, SM-ctl, and H7-atg as representative examples (the other samples have similar patterns). The inner $\mathrm{OH}$ bending vibration centers of lizardite and chrysotile are around $609 \mathrm{~cm}^{-1}, 630 \mathrm{~cm}^{-1}$, and $649 \mathrm{~cm}^{-1}$, which are assigned to the $\mathrm{OH}$ translational vibration mode. In the range of $\mathrm{OH}$ stretching, for antigorite, the peak at $3674 \mathrm{~cm}^{-1}$ is stronger than the peak at $3693 \mathrm{~cm}^{-1}$, which are both assigned to the outer $\mathrm{OH}$ vertical stretching vibration. The opposite relationship occurs for those peaks in lizardite and chrysotile. Antigorite also lacks the peak near $3700 \mathrm{~cm}^{-1}$ that is assigned to the inner $\mathrm{OH}$ stretching vibration. Figure 4 shows DWH14-lz, SM-ctl, and H7-atg as representative examples (the other samples have similar patterns). The detailed peak positions and band assignments of the samples are presented in Table 2.
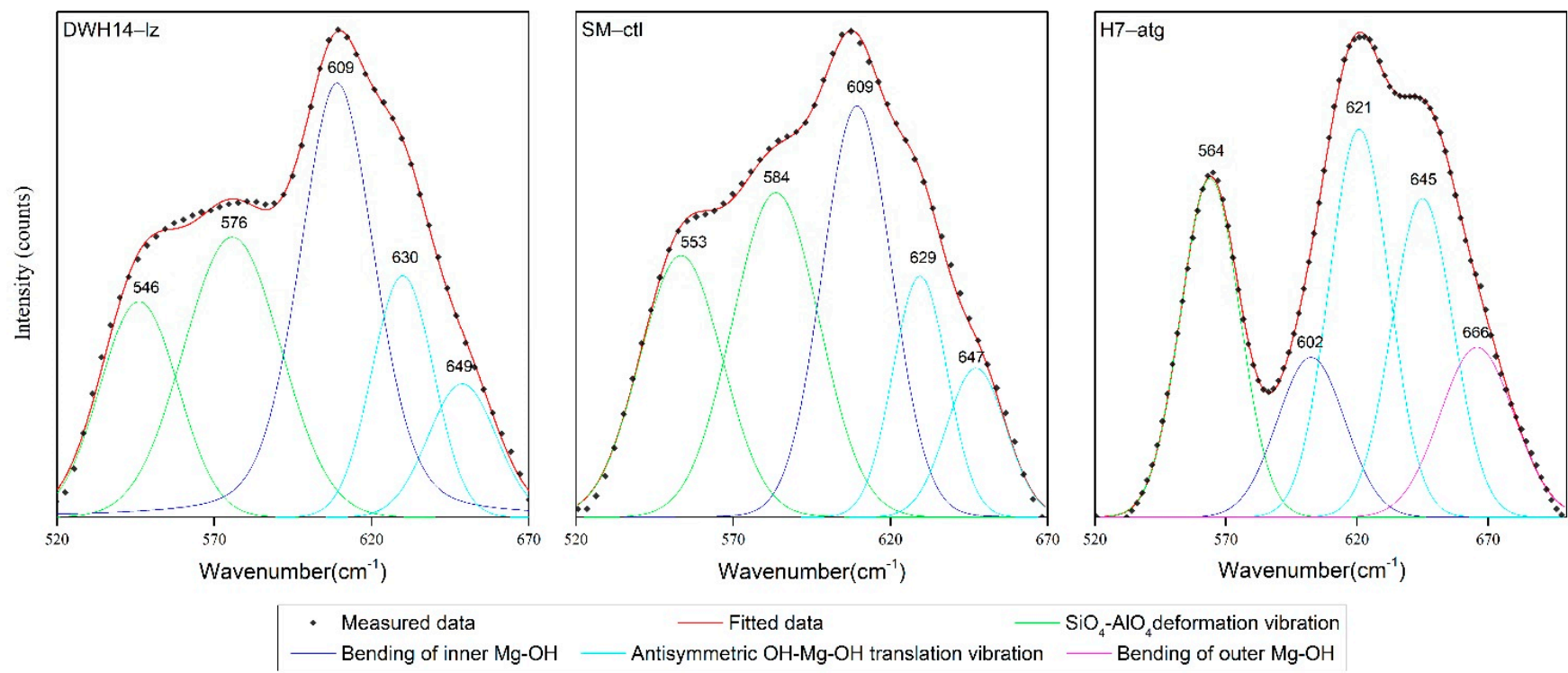

Figure 3. Band component analysis of the $520-700 \mathrm{~cm}^{-1}$ region with DWH14-lz as example of lizardite, SM-ctl as example of chrysotile, and H7-atg as example of antigorite.

\subsection{Characteristics of NIR}

Serpentine minerals have multiple secondary combination bands in the range $4000-4500 \mathrm{~cm}^{-1}$, with the strongest peak near $4280-4300 \mathrm{~cm}^{-1}$ (Figure $5 \mathrm{a}$ ). The band centers are listed in Table 3 . The results show that lizardite exhibits equal-strength double 
peaks near 4280 and $4301 \mathrm{~cm}^{-1}$. The $4304 \mathrm{~cm}^{-1}$ peak of chrysotile is stronger, and the $4279 \mathrm{~cm}^{-1}$ peak appears as a shoulder. Antigorite has a weaker shoulder peak at $4279 \mathrm{~cm}^{-1}$, and a new shoulder peak appears at $4315 \mathrm{~cm}^{-1}$.
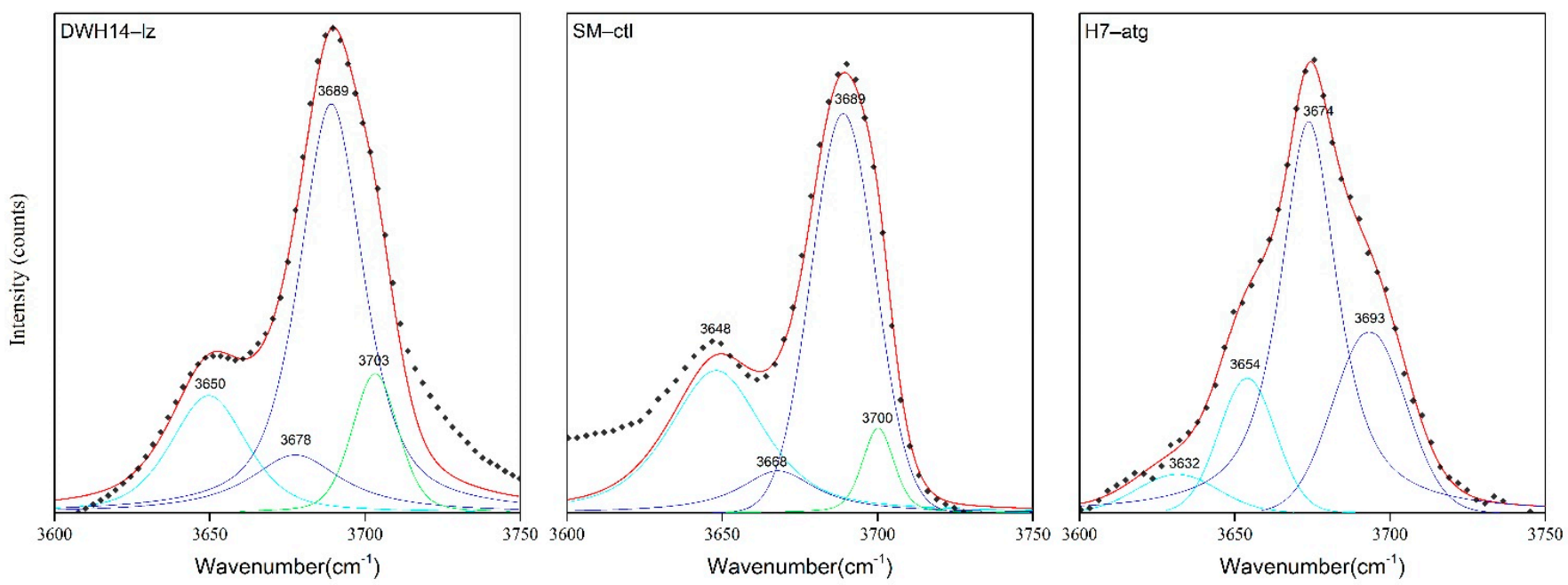

$\begin{array}{ll}\text { Measured data } & \text { Fitted data } \\ \text { Out-of-phase stretching inner-surface } \mathrm{OH} \longrightarrow \text { Inner OII stretching } \\ \text { Ondetching inner-surface } \mathrm{OH}\end{array}$

Figure 4. Band component analysis of the $3600-3750 \mathrm{~cm}^{-1}$ region with DWH14-lz as example of lizardite, SM-ctl as example of chrysotile, and H7-atg as example of antigorite.

Table 2. The MIR bands related to the serpentine samples and their assignments (in $\mathrm{cm}^{-1}$ ).

\begin{tabular}{|c|c|c|c|c|c|c|c|}
\hline Band Assignment [14,18-23] & DWH14-lz & ZH41-1z & Z3-lz & SZ17-lz & SM-ctl & H7-atg & H11-atg \\
\hline Antisymmetric $\mathrm{Mg}-\mathrm{OH}$ translation & 441 & 441 & 438 & 438 & 435 & 436 & 435 \\
\hline $\mathrm{Mg}-\mathrm{OH}$ translation $+v_{6}(\mathrm{e}) \mathrm{SiO}_{4}$ & 462 & 462 & 463 & 463 & 454 & 449 & 449 \\
\hline \multirow{2}{*}{$\mathrm{SiO}_{4}-\mathrm{AlO}_{4}$ deformation vibration } & 546 & 553 & 551 & 553 & 553 & \multirow{2}{*}{564} & \multirow{2}{*}{564} \\
\hline & 576 & 580 & 580 & 583 & 584 & & \\
\hline Bending of inner $\mathrm{Mg}-\mathrm{OH}$ & 609 & 609 & 609 & 610 & 609 & 602 & 600 \\
\hline Antisymmetric $\mathrm{OH}-\mathrm{Mg}-\mathrm{OH}$ & 630 & 630 & 629 & 630 & 629 & 621 & 619 \\
\hline translation vibration & \multirow[t]{2}{*}{649} & \multirow[t]{2}{*}{648} & \multirow[t]{2}{*}{646} & \multirow[t]{2}{*}{649} & \multirow[t]{2}{*}{647} & 645 & 644 \\
\hline Bending of outer $\mathrm{Mg}-\mathrm{OH}$ & & & & & & 666 & 666 \\
\hline Si-O stretching vibration & 961 & 962 & 963 & 956 & 963 & 970 & 969 \\
\hline $\mathrm{Si}-\mathrm{O}_{\mathrm{b}}-\mathrm{Si}$ stretching vibration & 1022 & 1022 & 1024 & 1018 & 1026 & 994 & 993 \\
\hline $\mathrm{Si}-\mathrm{O}_{\mathrm{nb}}$ stretching vibration & 1080 & 1078 & 1080 & 1079 & 1080 & 1080 & 1077 \\
\hline Outer $\mathrm{OH}$ sloping stretching vibration & 3650 & 3647 & 3649 & 3648 & 3648 & $\begin{array}{l}3632 \\
3654\end{array}$ & $\begin{array}{l}3632 \\
3653\end{array}$ \\
\hline \multirow{2}{*}{ Outer $\mathrm{OH}$ vertical stretching vibration } & 3678 & $3665 w$ & $3670 w$ & 3667 & 3668 & 3674 & 3674 \\
\hline & 3689 & 3688 & 3688 & 3688 & 3689 & 3693 & 3696 \\
\hline Inner $\mathrm{OH}$ stretching vibration & 3703 & 3704 & 3705 & 3705 & 3700 & & \\
\hline
\end{tabular}

All of the spectra have a large number of disordered but clear peaks in the ranges $5100-5500 \mathrm{~cm}^{-1}$ and $7000-7500 \mathrm{~cm}^{-1}$ (Figure 5b). Bishop [24] suggested that these bands are probably due to a small amount of $\mathrm{H}_{2} \mathrm{O}$ molecules trapped at grain boundaries or are associated with impurities in the samples. However, our experimental results show that the peak position does not shift due to the influence of the type of serpentine and contents of the impurities. Thus, it is unlikely to be caused by isomorphism and is likely related to the water in the crystal structure. Cheng [10] pointed out that the unbound water in the interlayer structure of clay minerals causes a series of absorption peaks near $5260 \mathrm{~cm}^{-1}$ and $7150 \mathrm{~cm}^{-1}$, which are generally not assigned. There is a broad absorption band at $5000-5300 \mathrm{~cm}^{-1}$ in chrysotile, which is reported to be caused by a large amount of adsorbed 
water in the tubular structure. A similar broad absorption band was observed in the range of $3300-3500 \mathrm{~cm}^{-1}$.
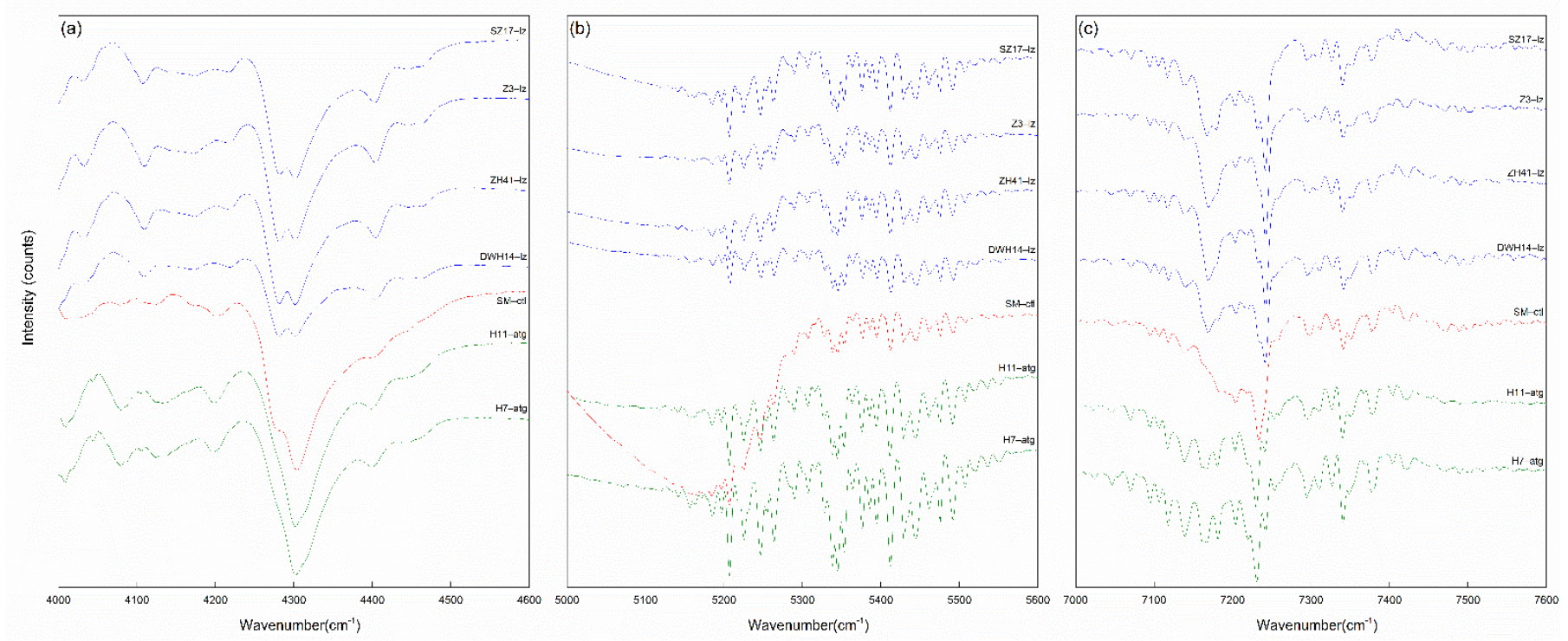

Figure 5. NIR spectra of the serpentine samples. (a) Range of the $\mathrm{OH}$-combination bands $\left(4000-4600 \mathrm{~cm}^{-1}\right)$; (b) adsorbed water bands $\left(5000-5600 \mathrm{~cm}^{-1}\right)$; (c) range of the $\mathrm{OH}$-stretching overtone bands $\left(7000-7600 \mathrm{~cm}^{-1}\right)$.

Table 3. The bands in the range $4000-4600 \mathrm{~cm}^{-1}$ for the related samples (in $\mathrm{cm}^{-1}$ ).

\begin{tabular}{ccccccccc}
\hline $\begin{array}{c}\text { J. L. Post } \\
\text { [18] }\end{array}$ & $\begin{array}{c}\text { Baron } \\
\text { [19] }\end{array}$ & DWH14-lz & ZH41-lz & Z3-1z & SZ17-lz & SM-ctl & H7-atg & H11-atg \\
\hline 4010 & 4001 & 4009 & 4009 & 4009 & 4009 & 4009 & 4009 & 4009 \\
& & & & & & & 4044 & 4043 \\
4076 & 4077 & & & & & 4078 & 4079 & 4079 \\
4123 & 4121 & 4109 & 4109 & 4109 & 4108 & 4106 & 4105 & 4105 \\
4196 & 4199 & 4218 & 4218 & 4218 & 4218 & 4201 & 4197 & 4197 \\
4279 & 4274 & 4281 & 4281 & 4281 & 4281 & 4279 & 4279 & 4279 \\
4303 & 4307 & 4301 & 4301 & 4301 & 4301 & 4304 & 4302 & 4301 \\
4315 & & & & & & & 4315 & 4315 \\
4401 & 4409 & 4404 & 4404 & 4404 & 4404 & 4401 & 4400 & 4400 \\
\hline
\end{tabular}

The first fundamental overtone of the $\mathrm{OH}$ stretching vibrations of layered silicate is in the range $7160-7300 \mathrm{~cm}^{-1}$ (Figure $5 \mathrm{c}$ ). The statistics and assignments of the peaks are presented in Table 4. The weak interlayer water peaks were excluded. There are two strong peaks at 7170 and $7240 \mathrm{~cm}^{-1}$ in the lizardite spectra. Chrysotile only has a strong peak at $7233 \mathrm{~cm}^{-1}$, a weak shoulder peak at $7234 \mathrm{~cm}^{-1}$, and very weak peak at $7170 \mathrm{~cm}^{-1}$. Antigorite has a strongest peak at $7231 \mathrm{~cm}^{-1}$ and a clear peak at $7243 \mathrm{~cm}^{-1}$. It is not accurate to judge the existence of chrysotile solely on whether there is strip near $7233 \mathrm{~cm}^{-1}$ [25].

Table 4. The bands in the range $7000-7600 \mathrm{~cm}^{-1}$ for the related samples (in $\mathrm{cm}^{-1}$ ).

\begin{tabular}{cccccccc}
\hline Outer OH & DWH14-lz & ZH41-lz & Z3-lz & SZ17-lz & SM-ctl & H7-atg & H11-atg \\
\hline$v_{\mathrm{OH}-\mathrm{s}}$ & 7170 & 7168 & 7170 & 7167 & 7170 & 7168 & 7167 \\
$v_{\mathrm{OH}-\mathrm{s}}+$ & 7204 & 7203 & 7204 & 7204 & 7204 & 7204 & 7203 \\
$v_{\mathrm{OH}-\mathrm{v}}$ & 7234 & 7233 & 7233 & 7231 & 7233 & 7231 & 7230 \\
$v_{\mathrm{OH}-\mathrm{v}}$ & 7241 & 7241 & 7242 & 7241 & 7243 & 7243 & 7241 \\
$v_{\mathrm{OH}-\mathrm{v}}$ & & & & & & & \\
\hline
\end{tabular}




\section{Discussion}

The band frequency relationships between the MIR and NIR spectra were determined via trial-and-error summations. Post [15] pointed out that there are two theories regarding the assignment of the peak at $4300 \mathrm{~cm}^{-1}$. The stretching vibrations of the inner $\mathrm{OH}$ and outer $\mathrm{OH}$ are combined with different $\mathrm{OH}$ bending vibrations [18,26,27]. However, according to Bishop [17], peaks at 4280 and $4300 \mathrm{~cm}^{-1}$ correspond to the combination of the internal or external hydroxyl stretching vibration and the bending vibration of the same hydroxyl group, and the peak at $4315 \mathrm{~cm}^{-1}$ has not been analyzed. Combined with the data obtained in our experiment, we determined a more suitable peak assignment: the absorption band at $4280 \mathrm{~cm}^{-1}$ was attributed to the combination of the $3650 \mathrm{~cm}^{-1}$ assigned outer $\mathrm{OH}$ sloping stretching vibration and the $630 \mathrm{~cm}^{-1}$ assigned antisymmetric $\mathrm{OH}-\mathrm{Mg}-\mathrm{OH}$ translation vibration. Additionally, the band at $4300 \mathrm{~cm}^{-1}$ was attributed to the combination of the $3690 \mathrm{~cm}^{-1}$ assigned outer $\mathrm{OH}$ sloping stretching vibration and the $610 \mathrm{~cm}^{-1}$ assigned antisymmetric $\mathrm{OH}-\mathrm{Mg}-\mathrm{OH}$ translation vibration. The specific corresponding values of the three serpentine minerals are shown in Table 5. The outer $\mathrm{OH}$ sloping stretching vibration of H7-atg and H11-atg participates in the combination as a whole and the average value of $3643 \mathrm{~cm}^{-1}$ has good results. All of the errors are within $10 \mathrm{~cm}^{-1}$ [28]. The peak at $4279 \mathrm{~cm}^{-1}$ is not obvious due to the weak OH sloping stretching vibration in antigorite. The combination of $3674 \mathrm{~cm}^{-1}$ assigned to the outer $\mathrm{OH}$ vertical stretching vibration, with $620 \mathrm{~cm}^{-1}$ assigned to the antisymmetric $\mathrm{OH}-\mathrm{Mg}-\mathrm{OH}$ translation vibration, is strong and clear. The $3674 \mathrm{~cm}^{-1}$ peak also combines with the $645 \mathrm{~cm}^{-1}$ peak assigned to the antisymmetric $\mathrm{OH}-\mathrm{Mg}-\mathrm{OH}$ translation vibration, presenting as a shoulder peak at $4315 \mathrm{~cm}^{-1}$. In the other two kinds of serpentines, the peak intensity at $648 \mathrm{~cm}^{-1}$ is weak, so the $4315 \mathrm{~cm}^{-1}$ peak is difficult to observe. All of the samples exhibit an obvious peak near $4400 \mathrm{~cm}^{-1}$. Bishop [24] believes that $\mathrm{Fe}^{3+}$ replaces $\mathrm{Mg}$ and that the formation of $\mathrm{Fe}^{3+} \mathrm{Mg}_{2}-\mathrm{OH}$ causes this peak, which demonstrates that the substitution of $\mathrm{Fe}$ for $\mathrm{Mg}$ in the octahedral layer is common in serpentine.

The $\mathrm{OH}$ group vibration of serpentine in the mid-infrared region corresponds to the first fundamental overtone of the $\mathrm{OH}$ group stretching vibrations in the near-infrared range. The specific corresponding values of the three types of serpentines are presented in Table 6. The peak near $7170 \mathrm{~cm}^{-1}$ belongs to the overtone of the outer $\mathrm{OH}$ sloping stretching vibration near $3648 \mathrm{~cm}^{-1}$. The peak near $7204 \mathrm{~cm}^{-1}$ belongs to the overtone of the combination of the outer $\mathrm{OH}$ sloping and vertical stretching vibrations near 3648 and $3689 \mathrm{~cm}^{-1}$. The peaks near 7233 and $7241 \mathrm{~cm}^{-1}$ belong to the overtone of the outer $\mathrm{OH}$ vertical stretching vibration. The outer $\mathrm{OH}$ sloping stretching vibration of antigorite also participates in the overtone as a whole.

The overtone of the vertical stretching vibration of the inner $\mathrm{OH}$ group should be around $7273 \mathrm{~cm}^{-1}$, but there is no absorption in the spectrum at this position. It is possible that the vibrating direction of the $\mathrm{OH}$ group is limited, and thus the overtone vibrations cancel each other.

Due to the non-ideality of the structure and composition, the average factor between the $\mathrm{OH}$ stretching vibration and its overtone is $1.965(+0.0026,-0.0037)$ rather than 2 , which is consistent with Bishop [17] but more accurate. Among the samples, the average factor of samples from the Hanzhong area is less than 1.965, while the average factor of samples from the Xiuyan area is greater than 1.965, which may be used as the basis for origin differentiation, although future experiments with more samples will be required to confirm. 
Table 5. The major NIR bands in the range $4000-4600 \mathrm{~cm}^{-1}$ related to the serpentine samples and their corresponding MIR peaks (in $\mathrm{cm}^{-1}$ ).

\begin{tabular}{|c|c|c|c|c|c|c|c|c|c|c|c|c|c|c|}
\hline & $\begin{array}{c}\text { Measured } \\
\text { Peak }\end{array}$ & $\begin{array}{l}\text { Lizardite } \\
\text { Fundamental } \\
\text { Peaks }\end{array}$ & $\begin{array}{c}\text { Theoretical } \\
\text { Peak }\end{array}$ & $\Delta$ & & $\begin{array}{c}\text { Measured } \\
\text { Peak }\end{array}$ & $\begin{array}{c}\text { Chrysotile } \\
\text { Fundamental } \\
\text { Peaks }\end{array}$ & $\begin{array}{c}\text { Theoretical } \\
\text { Peak }\end{array}$ & $\Delta$ & & $\begin{array}{l}\text { Measured } \\
\text { Peak }\end{array}$ & $\begin{array}{c}\text { Antigorite } \\
\text { Fundamental } \\
\text { Peaks }\end{array}$ & $\begin{array}{c}\text { Theoretical } \\
\text { Peak }\end{array}$ & $\Delta$ \\
\hline \multirow{2}{*}{ DWH14-lz } & 4281 & $3650+630$ & 4280 & 1 & \multirow{8}{*}{ SM-ctl } & 4279 & $3648+629$ & 4277 & 2 & & 4279 & $3643 *+645$ & 4288 & 9 \\
\hline & 4301 & $3689+609$ & 4298 & 3 & & 4304 & $3689+609$ & 4298 & 6 & H7-atg & 4302 & $3674+621$ & 4295 & 7 \\
\hline \multirow[b]{2}{*}{ ZH41-lz } & 4281 & $3647+630$ & 4277 & 4 & & & & & & & 4315 & $3674+645$ & 4319 & 4 \\
\hline & 4301 & $3688+609$ & 4297 & 4 & & & & & & & 4279 & $3643 *+644$ & 4288 & 9 \\
\hline \multirow[b]{2}{*}{ Z3-lz } & 4281 & $3649+629$ & 4278 & 3 & & & & & & H11-atg & 4301 & $3674+619$ & 4295 & 6 \\
\hline & 4301 & $3688+609$ & 4297 & 4 & & & & & & & 4315 & $3674+644$ & 4319 & 4 \\
\hline \multirow[t]{2}{*}{ SZ17-lz } & 4281 & $3648+630$ & 4278 & 3 & & & & & & & & & & \\
\hline & 4301 & $3688+610$ & 4298 & 3 & & & & & & & & & & \\
\hline
\end{tabular}

Table 6. The major NIR bands in the range $7000-7600 \mathrm{~cm}^{-1}$ related to the serpentine samples and their corresponding MIR peaks (in $\mathrm{cm}^{-1}$ ).

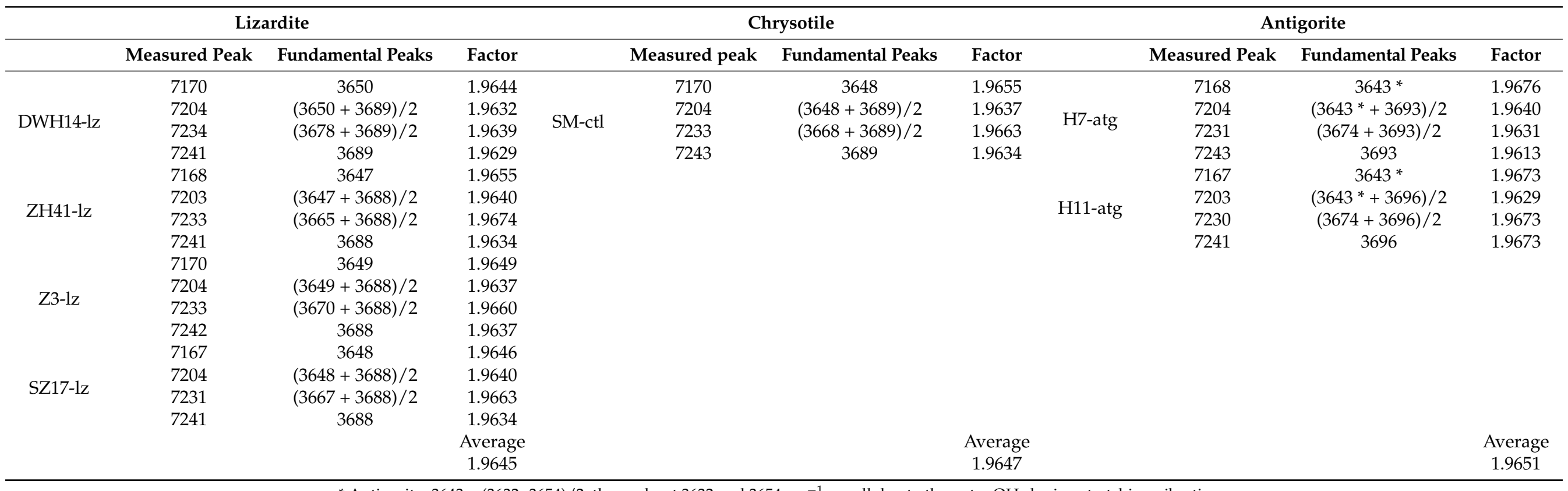

* Antigorite: $3643=(3632+3654) / 2$, the peaks at 3632 and $3654 \mathrm{~cm}^{-1}$ are all due to the outer $\mathrm{OH}$ sloping stretching vibration. 


\section{Conclusions}

1. There are obvious differences in the infrared spectrum of the three serpentine minerals. Lizardite has two equal-height peaks at 4280 and $4300 \mathrm{~cm}^{-1}$, and two strong peaks at 7170 and $7241 \mathrm{~cm}^{-1}$. Chrysotile has a shoulder peak at $4280 \mathrm{~cm}^{-1}$ and $7243 \mathrm{~cm}^{-1}$ and only one strong peak at $7233 \mathrm{~cm}^{-1}$. There are single strong peaks at $3674 \mathrm{~cm}^{-1}$, $4300 \mathrm{~cm}^{-1}$, and $7231 \mathrm{~cm}^{-1}$ and weak shoulder peaks at $4280 \mathrm{~cm}^{-1}$ and $4315 \mathrm{~cm}^{-1}$ for antigorite, with a clear peak at $7242 \mathrm{~cm}^{-1}$. These characteristic peaks are helpful in identifying and distinguishing between serpentine minerals.

2. In the range $4000-4600 \mathrm{~cm}^{-1}$, the serpentine peaks correspond to the $\mathrm{OH}$ secondary combination band region and in the range between 4280 and $4300 \mathrm{~cm}^{-1}$, it corresponds to a combination of sloping, vertical stretching, and bending vibrations of the outer $\mathrm{OH}$ groups. The $7000-7600 \mathrm{~cm}^{-1}$ band is the first fundamental overtone of the $\mathrm{OH}$ group stretching vibrations. The peaks at 7170, 7204, 7233, and $7242 \mathrm{~cm}^{-1}$ correspond to the overtone of the sloping stretching vibration of the outer $\mathrm{OH}$ group, the overtone combined sloping stretching vibration and vertical stretching vibration of the outer $\mathrm{OH}$ group, and the overtone of the vertical stretching vibration of the outer $\mathrm{OH}$ group, respectively.

3. Due to the non-ideal conditions, the actual position of the overtone peak is lower than the theoretical position. The factor of the first fundamental overtone of the $\mathrm{OH}$ group stretching vibration is about 1.965 .

Author Contributions: Conceptualization, M.H.; Data curation, S.W. and B.Z.; Formal analysis, S.W., M.Y. and B.Z.; Funding acquisition, F.W. and Q.L.; Investigation, Q.L.; Methodology, S.W. and M.Y.; Project administration, M.H.; Resources, F.W. and Q.L.; Writing-original draft, S.W. and B.Z.; Writing-review \& editing, M.H. and M.Y. All authors have read and agreed to the published version of the manuscript.

Funding: National Mineral Rock and Fossil Specimens Resource Center.

Data Availability Statement: Not applicable.

Conflicts of Interest: The authors declare no conflict of interest.

\section{References}

1. Yu, X.Y. Colored Gemmology, 2nd ed.; Geological Publishing House: Beijing, China, 2009; pp. 86-87.

2. Salzer, R. Practical Guide to Interpretive Near-Infrared Spectroscopy. By Jerry Workman, Jr. and Lois Weyer. Angew. Chem. Int. Ed. 2008, 47, 25. [CrossRef]

3. Li, Y.Q.; Jiang, S.Y.; Fan, W.W. Study on the Infrared Spectra of Chrysotiles in China. Chin. J. Geol. 1981, 3, $247-253$.

4. Xu, G.T.; Yuan, H.F.; Lu, W.Z. Development of Modern Near Infrared Spectroscopic Techniques and Its Applications. Spectrosc. Spectr. Anal. 2000, 2, 134-142.

5. Chu, X.L.; Yuan, H.F.; Lu, W.Z. Progress and Application of Spectral Data Pretreatment and Wavelength Selection Methods in NIR Analytical Technique. Anal. Instrum. 2006, 2, 1-10.

6. Zheng, A.B.; Yang, H.H.; Pan, X.P.; Yin, L.H.; Feng, Y.C. Identifying Multi-Class Drugs by Using Near-Infrared Spectroscopy and Variational Auto-Encoding Modeling. Spectrosc. Spectr. Anal. 2020, 40, 3946-3952.

7. Petriglieri, J.R.; Salvioli-Mariani, E.; Mantovani, L.; Tribaudino, M.; Lottici, P.P.; Laporte-Magoni, C.; Bersani, D. Micro-Raman mapping of the polymorphs of serpentine. J. Raman Spectrosc. 2015, 46, 953-958. [CrossRef]

8. Groppo, C.; Rinaudo, C.; Cairo, S.; Gastaldi, D.; Compagnoni, R. Micro-Raman spectroscopy for a quick and reliable identification of serpentine minerals from ultramafics. Eur. J. Mineral. 2006, 18, 319-329. [CrossRef]

9. Farmer, V.C. The Infrared Spectra Of Minerals; The Mineralogical Society of Great Britain \& Ireland: Middlesex, UK, $1974 ;$ p. 539.

10. Cheng, H.F.; Hao, R.W.; Zhou, Y. Visible and near-infrared spectroscopic comparison of five phyllosilicate mineral samples. Spectrochim. Acta Part A Mol. Biomol. Spectrosc. 2017, 180, 19-22. [CrossRef] [PubMed]

11. Li, X.J.; Yu, L.; Zu, E.D. Application of Near Infrared Spectroscopy in the Study of Gems. Spectrosc. Spectr. Anal. $2018,38,54-57$.

12. Zhang, S.J.; Deji, Z.; Qin, H.; Liu, H.; Luosang, D.; Cheng, H.F. The Structure of Layered Silicate Mineral and Their Vibrational Spectra Characteristics. China Non-Met. Miner. Ind. 2018, 2, 1-7.

13. Yariv, S. Infrared evidence for the occurrence of $\mathrm{SiO}$ groups with double-bond character in antigorite, sepiolite and palygorskite. Clay Miner. 1986, 21, 925-936. [CrossRef]

14. Kloprogge, J.T.; Frost, R.L.; Rintoul, L. Single crystal Raman microscopic study of the asbestos mineral chrysotile. Phys. Chem. Chem. Phys. 1999, 1, 2559-2564. [CrossRef] 
15. Post, J.L.; Borer, L. High-resolution infrared spectra, physical properties, and micromorphology of serpentines. Appl. Clay Sci. 2000, 16, 73-85. [CrossRef]

16. Trittschack, R.; Grobéty, B.; Koch-Müller, M. In situ high-temperature Raman and FTIR spectroscopy of the phase transformation of lizardite. Am. Mineral. 2012, 97, 1965-1976. [CrossRef]

17. Bishop, J.; Murad, E.; Dyar, M.D. The influence of octahedral and tetrahedral cation substitution on the structure of smectites and serpentines as observed through infrared spectroscopy. Clay Miner. 2002, 37, 617-628. [CrossRef]

18. Uehara, S.; Shirozu, H. Variations in chemical composition and structural properties of antigorites. Mineral. J. 1985, 12, 299-318. [CrossRef]

19. Luce, R.W. Identification of serpentine varieties by infrared absorption. Geol. Sur. Prof. Pap. 1971, 750, $199-201$.

20. Rinaudo, C.; Gastaldl, D.; Belluso, E. Characterization of Chrysotile, Antigorite and Lizardite by FT-Raman Spectroscopy. Can. Mineral. 2003, 41, 883-890. [CrossRef]

21. Xue, L.; Wang, Y.Q.; Fan, J.L. Study on the Spectroscopy of Yellow Serpentine Jade. Laser Infrared 2009, 39, $267-270$.

22. Prencipe, M.; Noel, Y.; Marco Bruno, M.; Dovesi, R. The vibrational spectrum of lizardite- $1 \mathrm{~T}\left[\mathrm{Mg}_{3} \mathrm{Si}_{2} \mathrm{O}_{5}(\mathrm{OH})_{4}\right]$ at the $\Gamma$ point: A contribution from an ab initio periodic B3LYP calculation. Am. Mineral. 2015, 94, 986-994. [CrossRef]

23. Balan, E.; Saitta, A.M.; Mauri, F.; Lemaire, C.; Guyot, F. First-principles calculation of the infrared spectrum of lizardite. Am. Mineral. 2015, 87, 1286-1290. [CrossRef]

24. Bishop, J.L.; Lane, M.D.; Dyar, M.D.; Brown, A.J. Reflectance and emission spectroscopy study of four groups of phyllosilicates: Smectites, kaolinite-serpentines, chlorites and micas. Clay Miner. 2008, 43, 35-54. [CrossRef]

25. Jana Madejová, J.; Jankovič, L.; Pentrák, M.; Komadel, P. Benefits of near-infrared spectroscopy for characterization of selected organo-montmorillonites. Vib. Spectrosc. 2011, 57, 8-14. [CrossRef]

26. Hunt, G.R.; Ashley, R.P. Spectra of altered rocks in the visible and near infrared. Econ. Geol. 1979, 74, 1613-1629. [CrossRef]

27. King, T.V.; Clark, R.N. Spectral characteristics of chlorites and Mg-serpentines using high-resolution reflectance spectroscopy. J. Geophys. Res. Solid Earth 1989, 94, 13997-14008. [CrossRef]

28. Baron, F.; Petit, S. Interpretation of the infrared spectra of the lizardite-nepouite series in the near- and mid-infrared range. Am. Mineral. 2016, 101, 423-430. [CrossRef] 